\title{
Comparação entre sutura convencional com fio de poliester e sutura com grampos de aço inoxidáveis na lobectomia parcial pulmonar. Estudo experimental em cães (Canis familiaris)
}

\section{Poliester conventional suture compared with inox staples in partial lung lobectomy. Experimental study in dog (Canis familiaris)}

José Aurelino Damasceno Ferreira Filho', Amary Nascimento Junior ${ }^{2}$, Rogério Tortelly ${ }^{2}$, Firmino Mársico Filho ${ }^{2 / *}$, Paulo Roberto do Nascimento Loureiro², José Renato Borges Junqueira ${ }^{2}$, Marcos Vinícios Mota Pires ${ }^{3}$

\section{Resumo}

Oito cães mestiços, hígidos, machos e fêmeas, com peso variando entre 12 e $20 \mathrm{~kg}$, foram submetidos à lobectomia parcial direita dos lobos apical e mediastínico, utilizando-se respectivamente, sutura com grampeadores automáticos e fio de poliester trançado recoberto por silicone, com o objetivo de se comparar ambas as técnicas. Os cães foram sacrificados 15 dias após a cirurgia, quando foram necropsiados e realizados os exames histopatológicos nas linhas de sutura. Concluiu-se que o uso do grampeador diminui o tempo cirúrgico e anestesiológico, apresentando menor manipulação do órgão, facilitando as manobras cirúrgicas, além de permitir melhor controle da aeroestasia e hemorragia no transoperatório. Não foram observadas diferenças histopatologicas significativas quanto ao processo cicatricial.

Palavras chaves: lobectomia; pulmão; sutura pulmonar

\section{Introdução}

Os grampeadores metálicos cirúrgicos toracoabdominais podem ser utilizados na rafia de lobectomia pulmonar parcial, lobectomia completa, pneumectomia, ressecção de tumores, ligadura e divisão de pedículos vasculares, sintese de esôfago, fechamento de enterotomia e gastrotomia, anastomose e ressecção gastrointestinal, rafia do coto uterino, lobectomia hepática, esplenectomia parcial e prostatectomia parcial (Pavletic, 1990).

Em animais, lesões torácicas como cistos pulmonares, abscessos, torção de lobo pulmonar, corpo estranho, persistência de arco aórtico direito e neoplasias responderam satisfatoriamente ao tratamento cirúrgico com grampeadores (La Rue et al., 1987). Amosov e Berzowsky (1961) relata como principal vantagem a sua utilização na ressecção parcial pulmonar, pois é possível realizar várias ressecções próximas ao limite do foco de destruição retirando-se o mínimo possível de tecido sadio.

Segundo Walshaw (1994), os grampeadores metálicos são utilizados há mais de 30 anos em cirurgias torácicas na medicina humana, porém poucos relatos em medicina veterinária descrevem seu uso e técnicas para cirurgia pulmonar.

Este trabalho objetivou comparar a utilização da sutura convencional com o uso de grampos métalicos na lobectomia parcial em cães.

\section{Material e Métodos}

No trabalho foram utilizados oito cães (Canis familiaris Linnaeus, 1758), escolhidos aleatoriamente, de ambos os sexos e sem raça definida, com peso variando de 12 a 20 $\mathrm{kg}$, oriundos do Instituto de Medicina Veterinária Jorge Vaitsman, no Rio de Janeiro. Todos os animais receberam cuidados pré e pós-operatórios dentro dos princípios do código de ética experimental em animais formulados pela Sociedade Zoófila Educativa eAssociação Protetora dos Animais do Estado do Rio de Janeiro.

Os animais receberam como medicação préanestesica cloridrato de acepromazina ${ }^{4}(0,1 \mathrm{mg} / \mathrm{kg}$.i.v), seguido de pré-oxigenação com $\mathrm{O}_{2}$ a $100 \%$, através de máscara de Hall, durante 3 min. Posteriormente foram induzidos com tiopental sódico $\left(12,5 \mathrm{mg} / \mathrm{kg}\right.$. i.v) ${ }^{5} \mathrm{e}$ conectados a um circuito circular valvular com absorção de $\mathrm{CO}_{2}$ e mantidos com halotano ${ }^{6}$ em ventilação controlada manual. Como bloqueador neuro-muscular foi utilizado o brometo de pancuronio ${ }^{7}(0.1 \mathrm{mg} / \mathrm{kg}$.i.v).

Após o isolamento e anti-sepsia do campo operatório foi realizada a toracotomia lateral direita no quinto espaço intercostal e aplicado o afastador auto-estático de Finochietto. Verificada a sintopia dos órgãos na cavidade torácica, os lobos "alvo", apical e mediastínico, foram

\footnotetext{
1 Aluno do Curso de Pós-graduação, UFF

2 Faculdade de Veterinária, Universidade Federal Fluminense, UFF, Rua Vital Brazil Filho 64, 24320-340 Niterói, RJ, Brasil

${ }^{3}$ Acadêmico de Medicina Veterinária, UFF

* Bolsista do CNPq

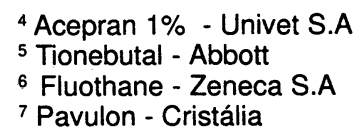


tracionados ao campo operatório e manuseados com auxílio de compressas úmidas, cada um no seu tempo cirúrgico.

No primeiro tempo procedeu-se à lobectomia parcial do lobo apical, com auxílio do grampeador toracoabdominal' colocado na parte distal do lobo; após sua aplicação, foi realizada uma excisão com auxílio de bisturi, paralela à fileira de grampos, utilizando-se o próprio grampeador como guia. Logo após, o lobo mediastínico foi tracionado e delimitado o local da excisão da parte distal do lobo que foi pinçado com uma hemostática e seccionado. A rafia foi realizada proximal à pinça com pontos contínuos em figura de "U", em dupla fileira, com fio inabsorvível de poliester trançado e siliconizado². Em ambos os procedimentos os lobos pulmonares remanescentes foram imersos em solução salina fisiológica morna, para testar a pneumostasia nas linhas de sutura. Após a aspiração dos fluidos presentes na cavidade torácica foi colocado e fixado um dreno torácico no nível do oitavo espaço intercostal, aproximadamente na altura da junção condro-costal, e conectado a um selo subaquático, em frasco único, com a finalidade de restabelecimento da pressão intratorácica, que foi removido após o restabelecimento da pressão negativa. Para fechamento da cavidade, foi realizada a aproximação das costelas com fio absorvível ${ }^{3}$ em pontos separados, em figura de " $X$ ", e dos planos musculares, subcutâneo e pele, com fio inabsorvível ${ }^{4} \mathrm{em}$ sutura contínua.

No pós-operatório os animais receberam como antibioticoterapia, enrofloxacina ${ }^{5}(5 \mathrm{mg} / \mathrm{kg}$.i.m) a cada 12 $h$, durante cinco dias e como medicação analgésica dipirona ${ }^{6}(20 \mathrm{mg} / \mathrm{kg}$.i.m) nas primeiras $48 \mathrm{~h}$.

Todos os animais foram sacrificados no $15^{\circ}$ dia de pósoperatório, utilizando-se, primeiramente, tiopental sódico até a perda dos reflexos e, em seguida, cloreto de potássio $^{7}$ a $19,1 \%$.

O material coletado foi fixado em solução de formol tamponado salino a 10\% (fragmento de parênquima pulmonar na região das suturas); na realização da clivagem da lesão do lobo apical os grampos metálicos foram retirados e o material processado para estudo microscópico.

\section{Resultados}

Macroscópicos - A hemostasia, observada no transoperatório, com o emprego da sutura com grampos metálicos, mostrou-se mais eficiente quando comparada com a sutura convencional.

\footnotetext{
$1 \mathrm{TA}-35$

2 DG Davis+ Geck

3 . Ethicon

4 Cirumédica

5 Flotril - Schering-plough

6 Dipirona-Hipolabor

${ }^{7} \mathrm{NaCl} 19,1 \%$ - Hipolabor
}

Durante o exame da cavidade torácica foi observado que os lobos apical e mediastínico apresentavam áreas de reparação de forma linear, com consistência firme, tonalidade avermelhada e medindo, respectivamente, 4 e 2 $\mathrm{cm}$.

Foram verificadas aderências em todos animais, principalmente no lobo mediastínico que, freqüentemente, se apresentava fixado à pleura parietal no local incisionado.

Foram observadas, em todos os animais, áreas de enfizema alveolar em ambos os lobos, principalmente nas áreas contínuas à lesão.

Microscópicos - Ao exame microscópico o lobo apical apresentou áreas de atelectasia com moderada a acentuada reação inflamatória, com predominância de mononucleares, exibindo ainda um material acelular acidófilo, fibrinóide e reação conjuntivo vascular ao lado de alterações granulomatosas.

A pleura e áreas contínuas apresentavam-se espessadas, provavelmente devido a uma moderada reação leucocitária e proliferação de um tecido mixóide. Em dois animais foram observados trombos organizados em áreas de atelectasia.

No lobo mediastínico, o exame microscópico revelou áreas de atelectasia, infiltradas por elementos inflamatórios, com predominância de mononucleares. No centro do processo foram encontrados corpos estranhos comparáveis a fio de sutura, ora imersos em material eosinofílico fibróide, ora constituindo formações nodulares devido à acentuada atividade de células gigantes multinucleadas. Também foram observadas áreas com neoformação capilar e por vezes presença de bronquiolite obliterante.

A pleura apresentou-se espessada, com presença de tecido conjuntivo frouxo mixóide e moderada reação leucocitária.

\section{Discussão}

A utilização de grampeadores permitiu uma diminuição do tempo cirúrgico, como observado por Androsov (1963), Farringer (1973), Scott et al. (1975), Hess et al. (1979), Hood (1984) e La Rue et al. (1987) e também uma maior facilidade técnica quando comparada com a sutura convencional (Takaro, 1984).

Apesar dos resultados com a utilização da técnica tradicional para a ressecção pulmonar, com o uso de grampeadores, foi evidenciado um melhor controle da aeroestasia assim como da hemorragia (Scott et al., 1976; Hess et al., 1979), apesar de Hood (1984) observar a necessidade de suturas extras quando da utilização dessa técnica. No presente trabalho somente em um animal foi necessária a sutura extra para controle do vazamento de ar e sangue quando do emprego da técnica de grampeamento. Acredita-se que a maior eficácia desse método se deva à eqüidistância pré-determinada dos grampos, fazendo com que houvesse uma perfeita distribuição 
no parênquima pulmonar. Já a sutura convencional tende a ser colocada a diferentes distâncias da linha de corte e aplicada com diferentes gradações de força, resultando em deformações nas bordas de sutura (Peteffy e Calabrese, 1979), além de provocar um maior sangramento durante a passagem da agulha (Hood, 1984).

A utilização da sutura metálica permitiu a excisão do fragmento distal do lobo próximo à linha de sutura, o que não ocorreu com a sutura convencional.Assim, torna-se um fator relevante em situações em que o paciente apresenta lesões pulmonares extensas, nas quais se faz necessário conservar o máximo de parênquima pulmonar normal, pois com o uso de grampeadores o mínimo de tecido sadio foi retirado juntamente com a lesão, observação também descrita por Betts e Takaro (1965).

Todos os animais do experimento foram sacrificados no $15^{\circ}$ dia, não apresentando nenhuma complicação pósoperatória, particularmente com respeito à formação de fístulas, como observado por Gerasimenko (1957) e Androsov (1963) com a utilização de ambos os tipos de sutura. Segundo Androsov (1963), o aparecimento de fístulas é, normalmente, de três a quatro e não estavam condicionadas a erros de técnica e sim a complicações pós-operatórias como neoplasias, tuberculose ou processos inflamatórios crônicos vizinhos às áreas de sutura, 0 que não aconteceu nesta pesquisa, pois os pacientes utilizados eram hígidos.

Durante a necropsia foram observadas áreas de enfizema pulmonar compensatório, provavelmente como uma resposta à perda de substância pulmonar ocasionada pela lobectomia, já que o espaço pleural permaneceu inalterado favorecendo hiperexpansão pulmonar. Segundo Robbins et al. (1986), outras causas prováveis de enfizema relacionam-se com a manipulação das vias aéreas e /ou ventilação com pressão positiva.

Em dois animais, quando foi utilizada a sutura com grampeadores, foram observados, microscopicamente, trombos organizados. Acredita-se que esse fato possa estar relacionado com a altura dos grampos $(3.5 \mathrm{~mm})$ utilizados em todos os animais. La Rue et al. (1987) descreveram que a seleção da altura dos grampos depende da espessura do tecido a ser comprimido; no atual trabalho o peso dos animais variou de 12 a $20 \mathrm{~kg}$. Segundo Santos (1978), as ligaduras dos vasos e as compressões sobre os mesmos podem determinar tromboses quando 0 endotélio dos vasos for comprometido. Logo, a altura dos grampos deverá ser suficiente para que ocorra um fechamento eficiente sem o esmagamento tecidual (Hood, 1984).

Outra hipótese a ser considerada a respeito da trombose foi a possibilidade de alguns desses animais possuírem lesões vasculares instaladas, apesar de não apresentarem sintomatologia clínica, já que são animais apreendidos nas ruas, em várias localidades.
Com relação ao processo cicatricial não foram encontradas variações quando comparados os dois métodos de sutura, não obstante Pêgo-Fernandes et al. (1990), utilizando o mesmo procedimento empregado na presente pesquisa, considerarem significativas as diferenças no processo cicatricial encontradas quando compararam o grampeamento com a sutura com fio de polipropileno. $O$ fio de poliester apresentou um reação tipo corpo estranho, com células gigantes multinucleadas que englobavam uma grande quantidade de material não digerível, caracterizando um processo inflamatório crônico compatível com o encontrado por Coelho (1995). No processo cicatricial com a técnica de grampeamento existe a possibilidade de retirada de alguns elementos histológicos presentes no processo inflamatório devido à retirada dos grampos antes do processamento histológico.

\section{Conclusões}

De acordo com as condições utilizadas no presente experimento, podemos concluir que: (1) o uso dos grampeadores diminui o tempo cirúrgico, com conseqüente diminuição do tempo anestesiológico, além de uma menor manipulação do orgão; (2) o uso de grampeadores permitiu um melhor controle da hemostasia e da aerostasia; (3) em ambas as técnicas, quando comparadas, não existem diferenças no processo cicatricial.

\section{Abstract}

Poliester conventional suture compared with inox staples in partial lung lobectomy. Experimental study in dog (Canis familiaris Linnaeus, 1758)

In this study, eight mongrel dogs, from both sexes, weight ranging from 12 to $20 \mathrm{~kg}$, were submitted to partial lobectomy of unilateral apical and mediastinal lobes, aiming to compare the sutures using stapler device or manual suture with siliconized polyester. The dogs were euthanized after 15 days post-surgical, and necropsied to have histological examination of sutures. The conclusion was that the stapler device minimizes the surgical time and tissue handling, facilitates the operating technique and permites a better control of air leakage and hemorrage.

Key words: lung stapler; pulmonary ressection; mechanical sutures

\section{Referências bibliográficas}

Amosov NM, Berzowsky KK 1961. Pulmonary resection with mechanical suture. J Thorac Cardiovasc Surg 41: 325-335.

Androsov PI 1963. New instruments for thoracic surgery. Diseases of the chest 44: 590-597.

Betts RH, Takaro $T$ 1965. Use of a lung stapler in pulmonary resection. Ann Thoracic Surgery 1(2): 197-202.

Coelho KIR 1995. Granulomas, p.137. In Barreto Neto, Patologia, Processos Gerais, $3^{\mathrm{a}}$ ed., UFF, Niterói. 
Farringer JL 1973. An auto-suture instrument. Am J Surg 125: 382-384.

Gerasimenko II 1957. The use of mechanical sutures on bronchi and vessels in operations on lung of tuberculous patients. Ministry of Health of the USSR: 45-51.

Hess JL; De Young DW, Grier RL 1979. Use of mechanical staples in veterinary thoracic surgery. J Am Anim Hosp Assoc 15: 569-573.

Hood RM 1984. Stapling techniques involving lung parenchyma. Surg Clin North Amer 64(3): 469-480.

La Rue SM, Withrow SJ, Wykes PM 1987. Lung resection using surgical staples in dogs and cats. Veter Surg 16(3):238-240.

Pavletic MM 1990. Surgical stapling devices in small animal surgery. Compend Contin Educ. Pract Vet 12: 1724-1740.

Pêgo-Fernandes $P$, Jatene FB, Aiello V, Hoshino H, Nakagama G, Miura F, Stolf $N$, Jatene AD 1990. Estudo comparativo entre sutura mecânica e manual em brônquios de cães. $J$
Pneumol 16(2): 71-74.

Peterffy A, Calabrese E 1979. Mechanical and convetional manual sutures of the bronchial stump. A comparative study of 298 patients. Scand J Thorac Cardiov Surg 13: 87-91.

Robbins SL, Cotram RS, Kumar V 1986. Patologia Estrutural e Funcional, $3^{\mathrm{a}}$ ed., $680 \mathrm{pp}$.

Santos JA 1978. Patologia Geral dos Animais Domésticos, $2^{\mathrm{a}}$ ed.

Scott RN, Faraci RP, Goodman DG 1975. The role of inflamation in bronchial stump healing. Ann Surg 81: 381-385.

Scott RN, Faraci RP, Aubrey H 1976. Bronchial stump closure techniques following pneumectomy. A serial comparative study. Ann Surg 116: 206-211.

Takaro T 1984. Use of staples in pulmonary surgery. Surg Clin North Am 64(3): 461-468.

Walshaw R 1994. Design and struture of the human lung, $p$. 224-271. In AP Fishman, Pulmonary Diseases and Disorders, McGraw-Hill, New York. 